\title{
Evaluation of Public Tendering Practices on Operational Performance in Electricity Sub-Sector Parastatals, Nakuru County, Kenya
}

\author{
Samson Chira Murigi ${ }^{1} \&$ Barrack Okello ${ }^{2}$ \\ ${ }^{2,2}$ Lecturer, Jomo Kenyatta University of Agriculture and Technology Jomo Kenyatta University of Agriculture \\ and Technology P.O Box 62000-00200, Nakuru
}

\begin{abstract}
Governments have an enormous task to provide adequate quality service to it's citizens in a timely manner. The public tendering practices have the potential to influence operational performance of energy sector parastatals. This is affected by the public tendering practices that the energy sector parastatals adopt in the procurement of given services or goods. This study therefore seeks to examine public tendering practices and operational performance of energy sector parastatals. The purpose of the study is the examination of effects of national open competitive tender practices, direct procurement tendering practices, request for quotation tendering practices, and restricted tendering practices. The theoretical review of this study is based on the transactional cost theory and theory of core competency.This study utilized the descriptive research design because the study wishes to evaluate the public tendering practices on operational performance of energy sector parastatal in Nakuru County, Kenya. The target population of this study consists of procurement officials and senior operations officers of Kenya Power, Geothermal Devolpment Company (GDC), and Kenya Electricity Generating Company (KenGen) within Nakuru County. There are 124 such officers within the three energy sector organizations in Nakuru. A sample size of 95 respondents was used. . The reliability of the study was examined using the cronbach alpha coefficient of a threshold of 0.7. The correlational analysis was undertaken between the variables in the study. The direct procurement method was positively, significantly (at 0.01 significance level) and strongly correlated operational performance at 0.830. From the study it can be concluded that short time required to procure items have no impact on operational performance while breakdown of critical items have a great effect on operational performance. On the same note it can be concluded that emergency/unforeseen requirements have a great impact on the operational performance of the energy sector parastatals. The findings led to the conclusion that suppliers with limited technology have a big impact on the operational performance.
\end{abstract}

Keywords: Direct Procurement, Operational Performance

\section{Introduction}

Globally public tendering are practiced in USA, England and statistics indicate that $76 \%$ of the parastatals in the public sector have successfully implemented them (Bekdik,2015). Regionally Ghana, Uganda, Tanzania have ensured that all Public Oranizations have implemented and are practicing Public Procurement practices (Amin, 2012). These countries have ensured that they have in place Public Procurement Act to regulate the organizations in Public sector.It is also evident that in all those countries there is in place Public Procurement Regulatory Authorities to regulate the Procurement.

Public tendering refers to refers to a process of submission made by a prospective supplier in response to an invitation to make an offer for the supply of goods or services, Amdany \& Kwasira (2016). On the other hand, Manaseer (2013) indicates that tendering is a formal and competitive process initiated by the Procurement function of an organization to put a contract or piece of work out to market. Mayavi (2015) examines tendering as the process by which a supplier, contractor or consultant makes an offer, proposal or quotation in response by a procuring entity. Tendering has also been examined as purchasing where by potential suppliers are invited to make and unequivocal offers of the price and terms which all acceptances shall be basis of subsequent contracts (Ohene, 2014). Finally, tendering has also been defined as process of ascertaining availability and price of materials in sealed covers which are opened and scrutinized at a predetermined time by a tender committee. The public tendering is the tendering process in which the procuring institution is a public sector entity or a government institution (Mayavi, 2015).

There are different public tendering practices including national competitive tender practices, direct procurement tendering practices, request for quotation tendering practices, restricted tendering practices, and international competitive tendering practices (Bekdik, 2015). According to Amdany \& Kwasira (2016), open tendering involves the procurement entity advertising a tender in the local newspaper and other technical press inviting contractors and potential suppliers to apply for tender to supply goods or services required by the 
organization. On the other hand, a restricted tendering method occurs where only a few invited or selected contractors are allowed to bid for any available tender. The direct tendering involves the procuring entity approaching a single supplier directly to provide a quote or tender for the goods, services or works. The various public tendering practices are discussed below;

The national open competitive tender practices are often preferred by diverse public entities and are often advocated for by procurement entities across the world.In Ghana, Kotoka (2012) notes that all the public procurement must be undertaken on an open competitive basis except in few allowed circumstances. The Ghanian law makes provision for the standards that must be met for open competitive tender practices. These include use of prescribed standard tender documents, and conditions for any tender modifications to be done on contract data sheets (Oppong, 2013). Through the open competitive tendering process, the successful tender for works contracts shall be the lowest evaluated tender price ascertained on the basis of criteria specified in the invitation documents, which shall include: the tender price subject to any margin of preference for domestic contractors; the potential for economic development, local involvement or technology transfer; and national security considerations (Oppong, 2013). The Ghanian procurement law introduces contract value thresholds that can be used for national open competitive tender for goods, works and technical services. The contract value thresholds for goods, works and technical services are 200 million to 2 billion Ghanian Cedis, 500 million to 15 billion Ghanian Cedis, and 200 million to 2 billion Ghanian Cedis respectively (Kotoka, 2012)

The Request for Quotation (RFQ) is a solicitation sent to potential suppliers containing in exacting detail a list or description of all relevant parameters of the intended purchase (Agerberg, 2012). The competitive tendering involves the potential suppliers being invited to make a firm and unequivocal offer of price and terms on which they may supply specified goods and services, which on acceptance, shall be the basis of a subsequent contract. The competitive tendering process can either be national or international based. The national competitive tendering involves the procuring entity specifying that only domestic suppliers may submit tenders. In contexts where the expertise required or goods that need to be supplied are not available locally then international tendering process can be used which is open to foreign companies (Bekdik, 2015).

There are different ways in which the public tendering practices impact on the operational performance of corporations. Khakata (2014) indicates that the public tendering practices impacts on the following operational performance metrics; improved financial performance, lead time performance, improved responsiveness, customer loyalty, innovation, quality products, and reduction in excess inventory levels and improvements in product/process design. The public tendering practices have the potential to influence operational performance of energy sector parastatals. The operational performance within the context of energy sector parastatals is concerned with effectiveness, efficiency, quality of service, customer lead times, and delivery dependability in the discharge of their respective mandates. However, the discharge of operational performance is dependent on the availability of key equipment, resources and technologies within the required timelines and quality (Amin, 2012). This is affected by the public tendering practices such as national open competitive tender practices, direct procurement tendering practices, request for quotation tendering practices and restricted tendering practices that the energy sector parastatals adopt in the procurement of given services or goods (Billow, 2014). The ability to acquire these items or services with ease, speed and cost efficiency is critical in the operational aspect on the parastatals.

Governments have an enormous task to provide adequate quality service to its citizens in a timely manner. Different public tendering practices can be used for the purposes of acquisition of goods and services to be used in public institutions. In this context, Public Procurement tendering practices have all been embraced by all energy sector agencies (Chesang, 2013).Amongst these public procurement tendering practices include direct procurement, request for quotation, restricted tendering, and national open tendering practices. The public tendering practices have the potential to influence operational performance of energy sector parastatals. The operational performance within the context of energy sector parastatals is concerned with effectiveness, efficiency, quality of service, customer lead times, and delivery dependability in the discharge of their respective mandates. However, the discharge of operational performance is dependent on the availability of key equipment, resources and technologies within the required timelines and quality. This is affected by the public tendering practices that the energy sector parastatals adopt in the procurement of given services or goods. This study therefore sought to examine public tendering practices and operational performance of energy sector parastatals. There is a gap in the literature gap that exists in which public tendering practices affect operational performance of an organization. Amongst the studies that have sought to examine conceptually similar aspects to this study include Khakata (2014) and Billow (2014). Khakata (2014) examined procurement methods and operational performance of state corporations in Kenya while Billow (2014) examined Procurement Performance And Operational Efficiency In Telecommunication Industry In Kenya. These studies while examining aspects of operational performance have not examined on the correlation between public tendering and operational performance in energy sector which was the focus of this study. 


\section{Theoretical Review}

\section{Literature Review}

The theoretical review of this study was based on the transactional cost theory and theory of core competency.

\section{Transactional Cost Theory}

The transactional cost theory was developed in 1979 by Oliver Williamson while working on concepts that were first developed by Ronald Coase (Amdany \& Kwasira ,2016). The theory was first developed for accounting purposes but has been expanded to other fields. The basis of the transactional cost theory is the concept of transactional cost. A transactional cost has been defined as the cost incurred in making an economic exchange of some sort or the cost of participating in the market. This cost is divided into three components; search and information costs, bargaining costs, and policing and enforcement costs (Njeru \& Ngugi, 2014). The search and information costs relates to the costs of examining on whether the required goods and services availability in the market as well as their prices. On the other hand, the bargaining costs involve the costs incurred in reaching an agreement between the seller and buyer such as legal costs of drawing contracts. Finally, the policing and enforcement costs are costs of ensuring that the terms of the contract are adhered to by both parties(Driscoll, Halliday, \& Stock, 2010).

The theory indicates that firms seek to minimize transactional costs of individual transactions that would take place between a buyer and seller in an open market. The theory seeks to explain the context in which it is beneficial to undertake a particular process within the firm and circumstances making it ideal to outsource a given process to outside firms (Maami, 2011). The theory of transaction cost economics also examines the boundaries between what is better performed within the firm and what should be outsourced. Within the context of transactional cost theory, procurement occurs as a result of need to acquire services and goods from external suppliers in the context that it is not economically viable to produce those goods in house. However, in the procurement of the services from external suppliers it is in the interest of the energy sector parastatals to reduce the transactional costs associated with the procurement.

The transactional cost theory is critical in context of operational performance and efficiency. The transactional cost theory indicates that firms should endeavour to produce the goods through external suppliers in contexts where they it is not viable to produce them in house. This enables the energy sector parastatals to save on the lead times of procuring critical services and equipment that are required for the work to progress. The services procured from outside the energy sector parastatals were also likely to be of higher quality especially where the organizations lack competent in house capacity.

\section{Theory of Core Competency}

The theory of core competency is attributed to C. K. Prahalad and Gary Hamel in 1980.The core competencies refers to the main strengths or strategic advantages that an organization including its combination of pooled knowledge and technical capacities that enable the organization to execute its mandates or objectives. The core competencies results from a specific set of skills or production techniques that deliver additional value to the customer. The theory indicates that all the items that are non-core activities of the organization must be outsourced to the best suppliers unless such activities give the institution a competitive advantage(Kiprop, 2014). Therefore, the firms should only retain inhouse those set of activities that are core to their organization(Driscoll et al., 2010). This implies that firms must be able to leverage on their strengths.

The mandates of the energy sector parastatals are varied. The Kenya Power is mandated to plan for sufficient electricity generation and transmission capacity to meet demand; building and maintaining the power distribution and transmission network and retailing electricity to its customers. On the other hand, Geothermal Development Company (GDC) is mandated to promote rapid development of geothermal resources in Kenya through surface exploration and drilling for steam. Kengen is involved in power generation in which it sells all the generated electricity to Kenya Power for distribution. In the context of the theory of core competency, the energy sector parastatals must limit their activities to their core mandates and core strengths. The energy sector parastatals must then outsource other activities that they don't have core strengths in.

\section{Direct Procurement Tendering Practices}

The direct procurement tendering method is applicable in Kenya when a public entity procures services or goods from a service provider without competition (Public Procurement Oversight Authority, 2016). There are diverse reasons under which the use of the direct procurement tendering practices is allowed in Kenya. According to Public Procurement Oversight Authority,(2016) direct procurement tendering processes is applicable when the purchase is for urgently needed remedial works, provided this is restricted to the minimum requirement to meet the urgent need until a procurement by other methods can be fulfilled. The other acceptable scenario for direct procurement is when the work can only be provided by one source for physical, technical or policy reasons e.g. requiring the use of proprietary techniques that are obtainable only from one source. Lack of reasonable alternatives or substitutes for the procured goods or services may push an organizational to direct 
procurement tendering processes. There are different areas of the direct procurement tendering practices that have a capacity to influence the operational aspects of the energy sector parastatals. The direct procurement has the capability to impacts on the operational performance of energy sector parastatals through reduction of the lead times compared to other tendering process. The lead times refers to the timelines that the parastatals gave to wait before the acquisition of the goods, services or works that they need to tender for. In this context, Tai (2015) notes that public sector institutions increase their operational performance through combining the resources and capabilities of their direct services and good suppliers through embedding inter-organizational cooperation in their direct procurement operations.

While the direct procurement tendering practices have positive effect on the operational aspects of the public sector firms, certain aspects of the direct procurement functions must be handled with care in order to realize intended benefits. In this context, Amin (2012) indicates that to obtain the benefits of direct procurement, firms not only have to streamline their procurement processes, but also have to strengthen the governance of their complicated interactions with their direct goods and services suppliers. The direct procurement often requires intensive communication and interaction between trading firms to ensure the alignment of activities between trading firms. Public entity firms therefore have the capacity to improve on their operational processes through direct procurement through intra-organizational process integration capability takes into account how a firm can effectively address issues of streamlining the processes of managing direct procurement requirements(Kinyua, 2015).

The use of direct procurement tendering processes for urgently needed remedial works, have significant impact on the operational performance of public utility firms. The use of direct procurement tendering processes in this context leads to quicker acquisition of goods and services that match the operational needs of public institutions(Vaidya, Sajeev, \& Callender, 2006). This is critically important as some of the operational processes and requirements of the energy sector firms implies that the firms stand to lose huge sums of money in case of breakdowns and workflow process breakdowns that are adequately addressed in a timely manner. The same may also expose the institutions to legal liabilities from their clients(Kiprop, 2014). In contexts, where there are is only one service provider due to diverse dimensions such as physical, technical or policy issues means that direct procurement saves on time for tendering as well as public funds. This has the possibility of quicker procurement of goods and services at cost efficient way.

\section{Objective of the Study}

To determine the effects of the direct procurement tendering practices on operational performance of energy sector parastatals in Nakuru County

\section{Research Hypothesis}

$\mathrm{H}_{0}$ : Direct procurement tendering practices have no significant effect on the operational performance of energy sector parastatals in Nakuru County

$\mathrm{H}_{\mathrm{A}}$ : Direct procurement tendering practices have significant effect on the operational performance of energy sector parastatals in Nakuru County

\section{Methodology}

The study used descriptive research design. The target population of this study consisted of procurement officials and senior operations officers of all selected electricity sector parastatals within Nakuru County. This was because these were the people with the knowledge on public tendering practices and operational perspective in their organizations. There were124 such officers within the three energy sector organizations in Nakuru. The sample size was calculated using the Yaro Yamane created a simplified formula for determining the sample size in 1967. This study adopted the simplified Yaro Yamane's formula as illustrated by below.

$$
\mathrm{n}=\frac{N}{1+N\left(e^{2}\right)}=\frac{124}{(1)+124\left(0.05^{2}\right)}=\frac{124}{1+0.31}=95 \text { respondents }
$$

Therefore a sample size of 95 respondents was used for the study. A total of 95 questionnaires was issued to respondents. $79(83.1 \%)$ questionnaires were returned. This response rate was deemed sufficient for the generalization of the study as indicated by Kombo \& Tromp (2009).

\section{Findings And Discussions}

Table 1: Frequency Tableof Direct Procurement Tendering Practices

\begin{tabular}{|c|c|c|c|c|c|}
\hline & $\begin{array}{l}\text { SA } \\
\text { Freq. }(\%)\end{array}$ & $\begin{array}{l}\text { A } \\
\text { Freq. }(\%)\end{array}$ & $\begin{array}{l}\mathrm{U} \\
\text { Freq. }(\%)\end{array}$ & $\begin{array}{l}\mathrm{D} \\
\text { Freq. }(\%)\end{array}$ & $\begin{array}{l}\text { SD } \\
\text { Freq. }(\%)\end{array}$ \\
\hline Short time to procure required items & $\begin{array}{l}31 \\
(39.2 \%)\end{array}$ & $\begin{array}{l}26 \\
(32.9 \%)\end{array}$ & $\begin{array}{l}18 \\
(22.8 \%)\end{array}$ & $\begin{array}{l}4 \\
(5.1 \%)\end{array}$ & $\begin{array}{l}0 \\
(0.0 \%)\end{array}$ \\
\hline Breakdown of critical items & 27 & 26 & 18 & 8 & 0 \\
\hline
\end{tabular}


Evaluation of Public Tendering Practices on Operational Performance in Electricity Sector

\begin{tabular}{|l|l|l|l|l|l|}
\hline & $(34.2 \%)$ & $(32.9 \%)$ & $(22.8 \%)$ & $(10.1 \%)$ & $(0.0 \%)$ \\
\hline Stock outs of critical items & 11 & 21 & 28 & 19 & 0 \\
& $(13.9 \%)$ & $(26.6 \%)$ & $(35.4 \%)$ & $(24.1 \%)$ & $(0.0 \%)$ \\
\hline Emergency/unforeseen requirements & 35 & 29 & 15 & 0 & 0 \\
& $(44.3 \%)$ & $(36.7 \%)$ & $(19.0 \%)$ & $(0.0 \%)$ & $(0.0 \%)$ \\
\hline Need for complex technology & 38 & 21 & 14 & 6 & 0 \\
& $(48.1 \%)$ & $(26.6 \%)$ & $(14 \%)$ & $(7.6 \%)$ & $(0.0 \%)$ \\
\hline Expensive Technology & 14 & 28 & 22 & 15 & 0 \\
& $(17.7)$ & $(35.4)$ & $(27.8 \%)$ & $(19.0 \%)$ & $(0.0 \%)$ \\
\hline Technology with limited suppliers & 48 & 21 & 10 & 0 & 0 \\
& $(60.8 \%)$ & $(26.6 \%)$ & $(12.7 \%)$ & $(0.0 \%)$ & $(0.0 \%)$ \\
\hline $\begin{array}{l}\text { Technologies touching on sensitive } \\
\text { operational aspects }\end{array}$ & 19 & 37 & 17 & 6 & 0 \\
& $(24.1 \%)$ & $(46.8 \%)$ & $(21.5 \%)$ & $(7.6 \%)$ & $(0.0 \%)$ \\
\hline
\end{tabular}

Most respondents strongly agreed that a short time required to procure required items significantly affects operational performance at $39.2 \%$. Only $5.1 \%$ disagreed to the above prompt as while $22.8 \%$ and $32.9 \%$ were undecided and Agreed respectively. $34.2 \%$ of the respondents strongly agreed that breakdown of critical items impacted operational performance while none of the respondents strongly disagreed to this question. However, $10.1 \%$ of the respondents disagreed, $22.8 \%$ were uncertain and 32.9\% Agreed. Those who disagreed that stock out of critical items $(24.1 \%)$ affected performance exceeded those who strongly agreed $(13.9 \%)$. Likewise those who were uncertain $(35.4 \%)$ exceeded those who agreed that stock outs of critical items impacted operational performance. While none of the respondents disagreed or strongly disagreed that emergency/unforeseen requirements impacted operational performance, $44.3 \%$ of them strongly agreed that emergency/unforeseen requirements impacted operational performance; $36.7 \%$ agreed and $19.0 \%$ were undecided. The percentage of respondents who dis-agreed (7.6\%) that need for complex technology affects performance was almost twice less than the percentage who were undecided $(14 \%)>$ Those who agreed were $26.6 \%$ while the percentage which strongly agreed was $48.1 \%$.

While still on technology, more respondents believed expensive technology impacted performance as opposed to those who were unsure (27.8\%) and those who disagreed $19.0 \%$. $35.4 \%$ agreed while $17.7 \%$ strongly agreed. Respondents who strongly agreed (60.8\%) that technology with limited suppliers impacted performance were highest $\mathrm{s}$ compared to $12.7 \%$ and $26.6 \%$ of respondents who were unsure and agreed respectively. $7.6 \%$ of the respondents disagreed that technologies touching on sensitive operational aspects affected performance, while $21.5 \%$ of the respondents were undecided, $46.8 \%$ agreed and $24.1 \%$ strongly agreed.

Table 2: Means and Standard Deviations of Direct Procurement Tendering Practices

\begin{tabular}{|l|l|l|l|l|}
\hline & Min & Max & Mean & Std. Dev. \\
\hline Short time to procure required items & 2 & 5 & 4.0633 & .91065 \\
\hline Breakdown of critical items & 2 & 5 & 3.9114 & .98956 \\
\hline Stock outs of critical items & 2 & 5 & 3.3038 & .99169 \\
\hline Emergency/unforeseen requirements & 3 & 5 & 4.2532 & .75902 \\
\hline Need for complex technology & 2 & 5 & 4.1519 & .97519 \\
\hline Expensive Technology & 2 & 5 & 3.5190 & .99821 \\
\hline Technology with limited suppliers & 3 & 5 & 4.4810 & .71362 \\
\hline Technologies touching on sensitive operational aspects & 2 & 5 & 3.8734 & .86776 \\
\hline
\end{tabular}

The responses ranged from disagree to strongly agree $(\min =2, \max =5)$ when respondents were asked whether short time required to procure required items affected growth. The respondents however were inclined to agree that this short time impacted performance (mean likert score of 4.0633 and std. dev. $=0.91065$ ) $>$ The same range of responses $(\min =2, \max =5)$ was observed when respondents were asked whether breakdown of critical items affected performance where on average respondents seemed to agree (3.91114, std. dev. $=0.98956)$. When prompted with Stock out of critical items on the performance, respondents tended to be unsure (average likert score of 3.3038 std. dev. $=0.99169)$. However it seemed to be generally accepted that emergency/unforeseen requirements impacted performance (mean likert score of 4.2532, std. dev. $=0.75902$ ) while the respondents ignored the strongly disagree and disagree prompts $(\min =3, \max =5)$.

Ignoring the strongly disagree prompt $(\min =2, \max =5)$, respondents were inclined to agree that need for complex technology impacted performance (mean= 4.1519 std. dev. $=0.97519$ ). Additionally, the respondents ignored strongly disagree and agree prompts when asked if expensive technology was key in determining performance $(\min =2, \max =5)$ though appearing undecided (average likert score $=3.519$ std. dev. $=$ 0.99821). Similarly, while ignoring strongly disagree and disagree options, respondents' general consensus was that technology with limited suppliers affects operational performance $(\min =3, \max =5$; mean likert $=4.4810$, std. 
deviation $=0.71362$ ). Additionally, respondents were inclined to agree that technologies touching on sensitive operations impacted performance (mean 3.8734, std. dev. $=0.86776$ )

\section{Conclusion}

Table 3; Correlational Analysis

\begin{tabular}{|l|l|}
\hline \multicolumn{1}{|c|}{ Operations Performance } \\
\cline { 2 - 2 } & $.830^{* * *}$ \\
\hline
\end{tabular}

**. Correlation is significant at the 0.01 level (2-tailed).

The correlational analysis was undertaken between the variables in the study. The direct procurement method was positively, significantly (at 0.01 significance level) and strongly correlated operational performance at 0.830 .

\section{Conculsions}

From the study it can be concluded that short time required to procure items have no impact on operational performance while breakdown of critical items have a great effect on operational performance. On the same note it can be concluded that emergency/unforeseen requirements have a great impact on the operational performance of the energy sector parastatals. The findings led to the conclusion that suppliers with limited technology have a big impact on the operational performance.

\section{References}

[1]. Amdany, R. M., \& Kwasira, J. (2016). Assessment of Tendering Methods on the Successful Implementation of Constituency Development Fund Projects in Njoro Sub-County ,. International Journal of Science and Research, 5(4), $1333-1341$.

[2]. Amin, A. (2012). Electronic Procurement and Organizational Performance Among Commercial State Corporations. Interdisciplinary Journal of Contemporary Research in Business, 3(4), 10-16.

[3]. Billow, H. (2014). Procurement performance and operational efficiency in telecommunication industry in Kenya. Journal of Business Management, 2(3), 45-52.

[4]. Driscoll, T., Halliday, A., \& Stock, R. (2010). Green Procurement Practices in the London Borough of Croydon. Journal of Business and Management, 2(3), 15-17.

[5]. Khakata, S. (2014). Procurement Methods and Operational Performance of State Corporation in Kenya. International Journal of Social Sciences and Enterpreneurship, 2(3), 14-19.

[6]. Kinyua, F. (2015). Public Procurement Process In Kenya: A Review Of Its Performance In The University Of Nairobi, Kenya. International Business Research, 3(4), 98-105.

[7]. Kiprop, P. (2014). Public Procurement Procedures and Supply Chain Performance in State Corporations in Kenya. IOSR Journal of Business and ManagementVer. I, 2(3), 74-75.

[8]. Kombo, D. K., \& Tromp, D. L. A. (2009). Proposal and Thesis Writing: An Introduction. Nairobi, Kenya: Paulines Publications Africa, Don Bosco Printing Press.

[9]. Maami, K. (2011). Factors that Influence Business Process Outsourcing Services by Horizon Call Centre in Nairobi, Kenya. International Journal for Management Science and Terchnology, 2(4), 75-80.

[10]. Njeru, S. E., \& Ngugi, P. (2014). Influence of supplier management on the implementation of effective procurement practices in tertiary public training institutions in Kenya, 2(May), 80-86.

[11]. Public Procurement Oversight Authority. (2016). Procurement Manual for Works. Retrieved from www.ppoa.go.ke/images/downloads/manuals/procurement_manual_for_works.pdf

[12]. Tai, Y. M. (2015). Exploring the performance impact of Web-based direct procurement systems: From the perspective of process integration. WSEAS Transactions on Information Science and Applications, 8(9), 380-390.

[13]. Vaidya, K., Sajeev, A. S. M., \& Callender, G. (2006). Critical Factors That Influence E-Procurement Implementation Success in the Public Sector. Journal of Public Procurement, 6(1\&3), 70-99. 